\title{
Prevalence of stroke and associated disability in Brazil: National Health Survey - 2013
}

\author{
Prevalência de acidente vascular cerebral e de incapacidade associada no Brasil: \\ Pesquisa Nacional de Saúde - 2013
}

\author{
Isabela M. Bensenor ${ }^{1,2}$, Alessandra C. Goulart ${ }^{1}$, Célia Landmann Szwarcwald³, Maria Lucia França Pontes \\ Vieira ${ }^{4}$, Deborah Carvalho Malta, ${ }^{4,5}$, Paulo A. Lotufo 1,2
}

\begin{abstract}
There is scarce data about prevalence of stroke in Brazil. The National Health Survey (PNS) is a community-based epidemiological survey, with a nationally representative sample to assess the absolute numbers with respective prevalence rates of stroke and post-stroke disabilities. It was estimated 2,231.000 stroke and 568,000 stroke cases with severe disabilities. The point prevalences was $1.6 \%$ and $1.4 \%$ in men and women, respectively. The prevalences of post-stroke disabilities were $29.5 \%$ for men and $21.5 \%$ for women. Stroke prevalence rates increased with aging, low education level, among people living in urban areas with no difference according to self-reported skin color. The degree of post-stroke disability was not statistically different according to sex, race, education level or living area. This new data from PNS show high stroke prevalence rates especially in older individuals without formal education and urban dweller, but the degree of stroke disability was not determined by the sociodemographic characteristics of the Brazilian population.
\end{abstract}

Keywords: stroke, prevalence, socio-demographic factors, disability, Brazil.

\section{RESUMO}

Há poucos dados sobre prevalência de acidentevascular cerebral (AVC) no Brasil.A Pesquisa Nacional de Saúde (PNS), um inquérito epidemiológico de base domiciliar, com amostra representativa nacional avaliou a prevalência de AVC no Brasil calculou o número absoluto estimado de pessoas com AVC e incapacidade por AVC e respectivas prevalências. Estimou-se 2.231 .000 pessoas com AVC e 568.000 com incapacidade grave. A prevalência pontual foi 1,6\% em homens e 1,4\% em mulheres, e a de incapacidade 29,5\% em homens e de 21,5\% em mulheres. A prevalência aumentou com a idade, nos menos escolarizados, residentes da zona urbana sem diferenças pela cor da pele auto-declarada. 0 grau de incapacidade pós-AVC não foi estatisticamente diferente segundo sexo, raça, nível de educação ou área de moradia. Os dados inéditos da PNS mostram altas taxas de prevalências de AVC principalmente em indivíduos mais idosos, sem educação formal, moradores de centros urbanos porém o grau de incapacidade pelo ACV não foi determinado pelas características sociodemográficas da população brasileira.

Palavras-chave: acidente vascular cerebral, prevalência, fatores sociodemográficos, incapacidade, Brasil.

Stroke mortality in Brazil has been reported the highest in South America for both genders ${ }^{1}$. Although stroke deaths have declined in the last decades ${ }^{2,3}$, recent mortality data also reveal cerebrovascular disease as the third cause of premature death after coronary heart disease and homicides ${ }^{4}$. However, the decrease in stroke mortality is not equally distributed across the country and it occurs mainly on the poorest areas of the country and among Blacks ${ }^{5,6,7}$.

Compared to previous mortality studies ${ }^{8}$, there are few studies evaluating the prevalence of stroke in Brazil according to sociodemographic characteristics ${ }^{9,10,11,12}$. These studies were carried out in cities or isolated regions reflecting more local realities than a national panorama of the disease. Pereira et al. found a prevalence of stroke in individuals over 60 years of $2.9 \%$ (3.2\% in men and $2.7 \%$ in women) in a city of the West side of state of Rio de Janeiro (Southeast region of Brazil $)^{9}$. The prevalence increased with ageing, regardless of living area (urban and rural) ${ }^{9}$. Abe et al. evaluated a low socioeconomic sample who lived at West area at the Butantan district of the city of São Paulo (Southeast region

\footnotetext{
'Universidade de São Paulo, Hospital Universitário, Centro de Pesquisa Clínica e Epidemiológica, Sao Paulo SP, Brazil;

¿Universidade de São Paulo, Faculdade de Medicina, Sao Paulo SP, Brazil;

${ }^{3}$ Fundação Oswaldo Cruz, Instituto de Comunicação e Informação Científica e Tecnológica em Saúde, Rio de Janeiro RJ, Brazil;

IInstituto Brasileiro de Geografia e Estatística, Rio de Janeiro RJ, Brazil;

5 Universidade Federal de Minas Gerais, Belo Horizonte MG, Brazil.

Correspondence: Isabela M. Benseñor; Centro de Pesquisa Clínica e Epidemiológica da USP, Hospital Universitário; Av. Lineu Prestes, 2565 / 30 andar; 05508-000 São Paulo SP, Brasil; E-mail: isabensenor@gmail.com

Conflict of interest: There is no conflict of interest to declare.

Received 18 March 2015; Received in final form 04 May 2015; Accepted 26 May 2015.
} 
of Brazil), and reported an age-adjusted prevalence of stroke of $4.6 \%$ for men and $6.5 \%$ for women ${ }^{10}$. Fernandes et al. reported the prevalence of stroke in a riverside community in the city of Coari located in the North region of the country (Amazonas state), and found that the prevalence was much higher in rural area (6.3\%) compared to urban area $(3.7 \%)$. Also, a higher frequency of stroke in women (4.1\%) compared to men $(3.0 \%)$ in the urban area was found, but no differences according to gender in rural area of Coari was reported $^{11}$. Another population-based study conducted in 3,391 individuals in the urban area of Porto Alegre (South region of Brazil) revealed a stroke prevalence of $8.4 \%$ detected by previous self-reported diagnosis or a questionnaire about symptoms of stroke ${ }^{12}$. Most of these studies assessed the prevalence of stroke in areas covered by the Health Family Program ${ }^{910,11}$. Differences in numbers between the four studies can be explained by local characteristics and the different diagnostic strategies, which were based on the medical diagnosis $^{9}$ or validated stroke questionnaire ${ }^{10,11,12}$.

The paucity of stroke data in the country, especially on the national scene, makes the National Health Survey (Pesquisa Nacional de Saúde- PNS) applied in 2013, a unique opportunity to describe the self- declared prevalence of stroke in Brazilian population ( $\geq 18 \mathrm{y}$-old) with representation for the whole country, including urban and rural areas, according to sex, race/self- reported skin color, education level and occupation.

\section{METHOD}

The National Health Survey (PNS) is a community-based epidemiological survey representative for Macro-Regions of Brazil, which included federated and capital units, metropolitan areas and rest of the federal units of the country. It belongs to the Integrated Household Surveys (SIPD) performed by the Brazilian Institute of Geography and Statistics (IBGE). For this survey, it was used the Master Sample of this system that permits a great geographical coverage and a gain of accuracy of the estimates ${ }^{13,14}$.

The minimum sample size was 1,800 households by federal unit, being planned, initially, a total sample of 81,767 households. Further, the sample was defined based on the desired accuracy level for estimating indicators of interest (proportions in certain categories of people). After the end of data collection, it was obtained records of 64,348 households interviews with 60,202 individuals interviewed, resulting in a non-response rate of $8.1 \%$.

Details about the process of sampling and weighting are provided in the publication of the results of the National Health Survey in somewhere ${ }^{13,14}$.

Based on the sample basis, it was calculated the point estimates of the stroke prevalence and its 95\% confidence interval $(95 \% \mathrm{CI})$. Prevalence rates were stratified by sex, age group (18-29, 30-59, 60-64, 65-74 and 75 years-old and over), education (no education and fundamental incomplete, complete primary and secondary incomplete, secondary education and higher incomplete, higher education) and race/self-reported skin color (White, Brown and Black). Prevalence rates were also presented by the total of the country and distributed between urban and rural areas. Expanded estimates for the adult population were also calculated.

All the data collection process of PNS was performed with the use of handheld computers (Personal Digital Assistant - PDA). The PNS questionnaire included a question about the self-reported diagnosis of stroke, "Has a doctor ever given you the diagnosis of stroke? "Additionally a question about the presence and degree of disability: "Overall, in what degree the stroke limits your daily activities (such as work or housework)”. The response options were 1-not limited to, 2-slightly, 3 moderately, 4-intensive, 5-very severe.

The PNS was approved by the National Ethics Committee (\#328 159, $26^{\text {th }}$ June 2013). The participation of adults in the survey was voluntary and that confidential information was guaranteed.

\section{RESULTS}

In this National Health Survey, it was estimated 2,231 million people with stroke. Stroke prevalence rates were $1.6 \%$ and $1.4 \%$ for men and women, respectively. The prevalence increased with ageing being $0.1 \%$ in the age strata 18 to 29 years-old and reaching $7.3 \%$ in the age groups above 75 years-old (Table 1). The prevalence was the highest in individuals with less schooling decreasing as the schooling increased. The prevalence has not changed according to the race/skin color. The prevalence was higher in urban areas compared to rural areas (Table 1).

Regarding to post-stroke functionality, it was estimated 568,000 people with intense degree or very severe limitations. The point prevalence of stroke disability was of $29.5 \%$ in men and $21.5 \%$ in women. Functional disability was not statistically different according to sociodemographic characteristics (Table 2).

\section{DISCUSSION}

For the first time, a Health National Survey describes the self-reported stroke prevalence and associated functional disability after acute event. A positive relationship between stroke prevalence and age, an inverse relationship between low education and high prevalences of stroke was found. Further, stroke prevalence was higher in urban areas than rural areas, but the prevalence of stroke disability was not statistically different according to sociodemographic characteristics analyzed. 
Table 1. Prevalence of stroke in adult population ( $\geq 18$ years) by sex, age group, race/skin color, educational level, occupation, and place of residence in the National Health Survey, 2013.

\begin{tabular}{|c|c|c|}
\hline Variables & Total population (expanded number * 1,000) & $\%(95 \% \mathrm{Cl})$ \\
\hline \multicolumn{3}{|l|}{ Sex } \\
\hline Male & 1,117 & $1.6(1.3-1.9)$ \\
\hline Female & 1,115 & $1.4(1.2-1.6)$ \\
\hline \multicolumn{3}{|l|}{ Age groups (years) } \\
\hline $18-29$ & 42 & $0.1(0.0-0.2)$ \\
\hline $30-59$ & 890 & $1.1(0.9-1.3)$ \\
\hline $60-64$ & 242 & $2.9(2.1-3.7)$ \\
\hline $65-74$ & 571 & $5.1(3.8-3.3)$ \\
\hline $75+$ & 486 & $7.3(5.8-8.8)$ \\
\hline \multicolumn{3}{|l|}{ Educational level } \\
\hline Without formal and incomplete fundamental & 1,559 & $2.7(2.4-3.1)$ \\
\hline Complete fundamental and incomplete intermediate & 186 & $0.8(0.6-1.1)$ \\
\hline Complete intermediate and incomplete superior & 378 & $0.8(0.5-1.0)$ \\
\hline Complete superior & 108 & $0.6(0.4-0.8)$ \\
\hline \multicolumn{3}{|l|}{ Race/skin color } \\
\hline White & 1076 & $1.5(1.3-1.8)$ \\
\hline Brown & 917 & $1.5(1.2-1.7)$ \\
\hline Black & 206 & $1.5(1.0-2.1)$ \\
\hline \multicolumn{3}{|l|}{ Work occupation } \\
\hline Yes & 505 & $0.6(0.4-0.7)$ \\
\hline No & 20 & $0.4(0.0-0.8)$ \\
\hline \multicolumn{3}{|l|}{ Residence } \\
\hline Urban & 2,020 & $1.6(1.4-1.8)$ \\
\hline Rural & 212 & $1.0(0.8-1.3)$ \\
\hline Brazil & 2,231 & $1.5(1.4-1.7)$ \\
\hline
\end{tabular}

95\%Cl: 95\% confidence interval.

Table 2. Prevalence of intense or very intense degree of disability due to stroke in adult population ( $\geq 18$ years) by sex, age, race/ethnicity, education level, occupation and place of residence due the stroke in the National Health Survey, 2013.

\begin{tabular}{|c|c|c|}
\hline Variables & Total population (expanded number * 1,000 ) & $\%(95 \% \mathrm{Cl})$ \\
\hline \multicolumn{3}{|l|}{ Sex } \\
\hline Male & 329 & $29.5(20.7-38.3)$ \\
\hline Female & 239 & $21.5(15.1-27.8)$ \\
\hline \multicolumn{3}{|l|}{ Age groups (years) } \\
\hline $18-29$ & 1 & $3.6(0.0-10.9)$ \\
\hline $30-59$ & 201 & $22.6(14.5-30.7)$ \\
\hline $60-64$ & 42 & $17.5(8.6-26.4)$ \\
\hline $65-74$ & 158 & $27.7(15.8-39.6)$ \\
\hline $75+$ & 165 & $34(23-45.1)$ \\
\hline \multicolumn{3}{|l|}{ Educational level } \\
\hline Without formal and incomplete fundamental & 466 & $29.9(23.2-36.6)$ \\
\hline Complete fundamental and incomplete intermediate & 33 & $17.9(6.4-29.5)$ \\
\hline Complete intermediate and incomplete superior & 57 & $15.1(5.6-24.6)$ \\
\hline Complete superior & 12 & $10.7(2.8-18.6)$ \\
\hline \multicolumn{3}{|l|}{ Race/skin color } \\
\hline White & 277 & $25.8(17.5-34)$ \\
\hline Brown & 220 & $24(16.2-31.9)$ \\
\hline Black & 69 & $33.4(17-49.7)$ \\
\hline \multicolumn{3}{|l|}{ Residence } \\
\hline Urban & 506 & 25 (19.2-30.9) \\
\hline Rural & 63 & $29.6(17.2-42)$ \\
\hline Brazil & 568 & $25.5(20.1-30.9)$ \\
\hline
\end{tabular}


The prevalence found in the PNS was lower than those reported by previous Brazilian studies were. However, the data are consistent with the age groups analyses performed in the PNS, which included adults $\geq 18$ years-old compared to the study of Pereira et al. ${ }^{9}$ and included individuals above 60 years-old in Abe and Fernandes studies, which performed their surveys in outskirts of cities of Sao Paulo (Sao Paulo State, Southeast region) and Coari ( Amazonas state, North region) with individuals over $35 \mathrm{y}$-old $^{10,11}$. Moreover, in the age group over 60 years, the prevalence of stroke was higher than that reported in a study performed in the interior region of Rio de Janeiro state, which showed a frequency of $3 \%$ for the same age group. It is possible that the data collected in the area covered by the Family Health Program in the state of Rio de Janeiro, has included a sample with worse sociodemographic indexes compared to our sample?

The point prevalences found in the PNS were higher in men than in women, which is consistent with the data published by Pereira et al. ${ }^{9}$, however these findings are in disagree with the studies of Abe and Fernandes that showed higher prevalence in their women populations ${ }^{10,11}$. In the studies held in São Paulo and Amazonas were used two strategies for the diagnosis of stroke: the first one used a self-reported similar question used in the PNS and the second used a brief questionnaire composed by six questions about stroke symptoms validated by a neurologist in a previous study ${ }^{15}$. The prevalence of most positive answers among women was associated with use of stroke symptoms questionnaire. As shown in other previous studies in the literature, women report more symptoms than men do and this could explain the higher prevalence using the questionnaire in relation to the diagnosis made by a single question, which did not detect any statistical differences between men and women ${ }^{16}$.

In the study of Copstein et al. performed in the city of Porto Alegre (South region), although it was not found statistically significant differences in the prevalence of cerebrovascular disease among men and women, some characteristics were identified as risk factors for stroke such as age, widowhood, smoking, hypertension, coronary heart disease and low education ${ }^{12}$.

The increase of stroke prevalence among less educated people is in accordance with the results found in mortality studies that described a significant influence of education as a marker for socioeconomic status in the distribution of the disease. The increased stroke prevalence among less educated has also been described in other previous national studies as a factor associated with worse long-term survival in stroke patients ${ }^{17,18}$. In the study of Goulart et al. performed in a prospective stroke cohort, which included ischemic and hemorrhagic stroke, after 4 years of follow-up, it was observed hazard ratios of death around 3 and 2 times higher among older individuals and those without formal education, respectively ${ }^{18}$. These increased rates could also impact on stroke prevalence.
Similar to Fernandes study, which was performed in river dwellers in the Amazon, stroke was more frequent in the urban than rural population. However, we did not find functional disability being influenced by the living area as Fernandes et al. found ${ }^{11}$. They described higher prevalence of disability among residents of rural areas compared to urban area, probably reflecting less access to health services and mainly to rehabilitation ${ }^{1}$.

In contrast to the results presented here, the prevalence of stroke according to self-reported race/skin color was similar in all categories. Mortality studies show higher mortality in Black due to the higher prevalence of hypertension in this population, as well, factors associated with worse socioeconomic status in this subset ${ }^{6}$. However, Judd et al. showed in the Reasons for Geographic and Racial Study Differences in Stroke (REGARDS), which evaluated stroke in high-risk areas in the United States, that the proportion of deaths from late post-stroke complications was higher in Whites, indicating a higher survival rate compared to brown or black individuals $^{19}$. Transposing this situation for our sample, similar frequencies by race might be occurred as a consequence of higher mortality in blacks compared to whites. Of note, the presence of severe functional disability was higher in black individuals in relation to browns and whites.

As the prevalence data depend on mortality and disability data depend on rehabilitation, it is difficult to understand what actually happens in the Brazilian population. Data from National Survey as PNS in Brazil are an important piece that will help in understanding the stroke prevalence in the whole country. Another important point is that the frequency of individuals with substantial disability is high ranging from 25 to $35 \%$ and showing once again the importance of rehabilitation in stroke survivors.

Some methodological limitations inherent to prevalence studies and the use of self-reported diagnoses or underdiagnoses might have occurred and could account for the lower prevalence rates found in this survey. Besides that, our findings show the concentration of stroke in male population, less educated, older and resident in urban areas. The data also show that at least a quarter of the population with a previous history of stroke has severe to very severe degree of disability. Although more data are needed to define the profile of the prevalence of stroke in Brazil, PNS provides for the first time, data on a national basis that will help compose the profile of cerebrovascular disease in Brazil.

The adoption in 2011 by the Ministry of Strategic Action Plan for the Health Confronting Chronic Noncommunicable Diseases (NCDs) in Brazil from 2011 to 2022, which provides actions to reduce NCDs by $2 \%$, adding circulatory diseases, including stroke as high priority on their agenda ${ }^{20}$. Several actions were carried out, as the organization of surveillance and monitoring and in this sense the realization of PNS contributed information on the occurrence of stroke and other diseases. There have been several health promotions, among 
them agreements to reduce food salt, educational measures as healthy eating and physical activity programs, regulation of tobacco-free environments, and improve care actions. We highlight the Ordinance no. 665, of April 12, 2012, which establishes financial incentives for creation of Urgent Care centers for patients with stroke in approving the Care Line, with professional training for attention in the emergency room, expansion of access to diagnostic tests, thrombolysis and coordination with primary care to promote comprehensive attention in this filed. It is hoped that these measures can reduce morbidity and mortality from stroke, which is already in decline in the country ${ }^{20,21}$.

\section{References}

1. Lotufo PA. Stroke in Brazil: a neglected disease. São Paulo Med J. 2005;123(1):3-4. doi:10.1590/S1516-31802005000100001

2. Lotufo PA, Goulart AC, Fernandes TG, Benseñor IM. A reappraisal of stroke mortality trends in Brazil (1979-2009). Int J Stroke. 2013;8(3):155-63. doi:10.1111/j.1747-4949.2011.00757.x

3. Souza MF, Alencar AP, Malta DC, Moura L, Mansur AP. Serial temporal analysis of ischemic heart disease and stroke death risk in five regions of Brazil from 1981 to 2001. Arq Bras Cardiol. 2006;87(6):735-40. doi:10.1590/S0066-782X2006001900009

4. GBD 2013 Mortality and Causes of Death Collaborators. Global, regional, and national age-sex specific all-cause and causespecific mortality for 240 causes of death, 1990-2013: a systematic analysis for the Global Burden of Disease Study 2013. Lancet. 2015:385(9963):117-71. doi:10.1016/S0140-6736(14)61682-2

5. Lotufo PA, Benseñor IM. Stroke mortality in Brazil: one example of delayed epidemiological cardiovascular transition. Int J Stroke. 2009;4(1):40-1. doi:10.1111/j.1747-4949.2009.00240.x

6. Lotufo PA, Goulart AC, Bensenor IM. Race, gender and stroke subtypes mortality in São Paulo, Brazil. Arq Neuropsiquiatr. 2007;65(3B):752-7. doi:10.1590/S0004-282X2007000500004

7. Lotufo PA, Bensenor IJ. Race and stroke mortality in Brazil. Rev Saúde Pública. 2013;47:1221-4. doi:10.1590/S0034-89102013000901201

8. Rodríguez T, Malvezzi M, Chatenoud L, Bosetti C, Levi F, Negri E et al. Trends in stroke mortality from coronary heart and cerebrovascular diseases in the Americas: 1970-2000. Heart. 2006;92(4):453-60. doi:10.1136/hrt.2004.059295

9. Pereira AB, Alvarenga H, Pereira Junior RS, Barbosa MT. [Stroke prevalence among the elderly in Vassouras, Rio de Janeiro state, Brazil, according to data from the Family Health Program]. Cad Saúde Pública. 2009;25(9):1929-36. Portuguese. doi:10.1590/S0102-311X2009000900007

10. Abe IM, Lotufo PA, Goulart AC, Benseñor IM. Stroke prevalence in a poor neighbourhood of São Paulo, Brazil: applying a stroke symptom questionnaire. Int J Stroke. 2011;6(1):33-9. doi:10.1111/j.1747-4949.2010.00538.x

11. Fernandes TG, Benseñor IM, Goulart AC, Tavares BM, Alencar AP, Santos IS et al. Stroke in the rain forest: prevalence in a ribeirinha community and an urban population in the Brazilian Amazon. Neuroepidemiology. 2014;42(4):235-42. doi:10.1159/000362210

12. Copstein L, Fernandes JG, Bastos G. Prevalence and risk factors for stroke in a population of Southern Brazil. Arq Neuropsiquiatr. 2013;71(4):294-300. doi:10.1590/0004-282X20130024
13. Ministério da Saúde (BR); Instituto Brasileiro de Geografia e Estatística. Pesquisa Nacional de Saúde 2013: percepção do estado de saúde, estilos de vida e doenças crônicas: Brasil, grandes regiões e unidades da Federação. Rio de Janeiro: Instituto Brasileiro de Geografia e Estatística; 2014 [cited 1014 Dec 22]. Available from: ftp://ftp.ibge.gov.br/PNS/2013/pns2013.pdf

14. Szwarcwald CL, Malta DC, Pereira CA, Vieira ML, Conde WL, Souza Júnior PR et al. [National Health Survey in Brazil: design and methodology of application]. Ciên Saúde Colet. 2014;19(2):333-42. Portuguese. doi:10.1590/1413-81232014192.14072012

15. Abe IM, Goulart AC, Santos Júnior WR, Lotufo PA, Benseñor IM. Validation of a stroke symptom questionnaire for epidemiological surveys. Sao Paulo Med J. 2010;128(4):225-31. doi:10.1590/S1516-31802010000400010

16. Aquino EM, Menezes GM, Amoedo MB. [Gender and health: consideration based on the National Household Sampling Survey]. Rev Saúde Pública. 1992;26(3):195-202. Portuguese. doi:10.1590/S0034-89101992000300011

17. Goulart AC, Fernandes TG, Alencar AP, Fedeli LMG, Benseñor IM, Lotufo PA. Low education as a predictor of poor one-year stroke survival in the EMMA Study (Study of Stroke Mortality and Morbidity in Adults), Brazil. Int J Stroke. 2012;7(7):E4 doi:10.1111/j.1747-4949.2012.00803.x

18. Goulart AC, Fernandes TG, Santos IS, Alencar AP, Benseñor IM, Lotufo PA. Predictors of long-term survival among first-ever ischemic and hemorrhagic stroke in a Brazilian stroke cohort. BMC Neurol. 2013:13(1):51. doi:10.1186/1471-2377-13-51

19. Judd SE, Gutiérrez OM, Newby PK, Howard G, Howard VJ, Locher $J L$ et al. Dietary patterns are associated with incident stroke and contribute to excess risk of stroke in black Americans. Stroke. 2013;44(12):3305-11. doi:10.1161/STROKEAHA.113.002636

20. Malta DC, Silva JB. [Brazilian Strategic Action Plan to Combat Chronic Non-communicable Diseases and the global targets set to confront these diseases by 2025: a review]. Epidemiol. Serv. Saúde. 2013;22(1):151-64. Portuguese. doi:10.5123/S1679-49742013000100016

21. Duncan BB, Chor D, Aquino EM, Bensenor IM, Mill JG, Schmidt MI et al. [Chronic non-communicable diseases in Brazil: priorities for disease management and research]. Rev Saúde Pública. 2012;46 Suppl 1:126-34. Portuguese. doi:10.1590/S0034-89102012000700017 